\title{
Experimental Observation of a Regression Dependence for Hydrodynamic Performance of the Regular Packing
}

\author{
Alexey Balchugov ${ }^{1},{ }^{*}$ and Artem Badenikov ${ }^{1}$ \\ ${ }^{1}$ Angarsk State Technical University, 665835, Angarsk, the Russian Federation
}

\begin{abstract}
The investigational studies of regression dependence of the new efficient regular packing bed's flow friction on gas velocity and liquid spray rate has been carried out. The tests were made by the procedure of a complete two-factor experiment. On account of experiment design matrix, there are four tests to be made to determine the regression dependence. It is found that the packing bed's flow friction builds up along with increase of superficial gas velocity and liquid spray rate. The regression dependence that puts packing bed's flow friction in touch with superficial gas velocity and liquid spray rate is procured. The specific dependence is valid for air velocity $1.21-3.12 \mathrm{~m} / \mathrm{sec}$ and liquid spray rate $0.0080-0.0304 \mathrm{~m}^{3} /\left(\mathrm{m}^{2} \cdot \mathrm{sec}\right)$. The conclusion on significance of regression dependencies has been made in terms of Student's t-test. The sufficiency of regression equation has been inspected via the Fisher's criterion. The resulting regression equation can be utilized in the design and engineering process of absorbers with the shock-spray packing.
\end{abstract}

The patent for the invention [1] offers the new high efficiency shock-spray regular packing designed for mass-transfer intensification in the gas-liquid absorption process. The flow friction is an important hydrodynamic quality of a packing [2]. The less the flow friction is, the less effort is needed to compress the gas before it enters the column [3]. Thus, the experimental determination of regression dependence of the packing's flow friction on gas velocity and liquid spray rate is important.

Figure 1 shows the structural diagram of the shock-spray packing [4]. The packing presented implements the shock-spray interaction principle between gas and liquid. The packing consists of vertically arranged corrugated plates (1 and 2). Plate (1) is fitted with flat horizontal pads (3). Plate (2) has slit trenches. Also, plate (2) is perforated: the void cross-section of plate 2 is equal to $22 \%$.

The tests to determine the regression dependence for hydrodynamic performance of the new packing have been made using the laboratory facility (figure 2). Packing bed faces (1) are made of organic glass to ensure observability. Packing bed consists of 22 identical contact stages. Single diamond-shaped cell (figure 1) is $0.055 \times 0.055 \mathrm{~m}$. Total packing bed height is $0.85 \mathrm{~m}$, width is $0.195 \mathrm{~m}$. There are stainless steel perforated baffles between

\footnotetext{
${ }^{*}$ Corresponding author: balchug@mail.ru
} 
contact stages. Width of slit trenches for gas and liquid passage is $0.006 \mathrm{~m}$. The equivalent packing diameter is $0.055 \mathrm{~m}$, the void space of packing bed is 0.82 .

During the laboratory tests the flow friction has been measured using the micromanometer (5) (figure 2). Air and water were used as working environments during the tests. The tests were conducted at a pressure of 1at and working environments temperature of $17^{\circ} \mathrm{C}$.

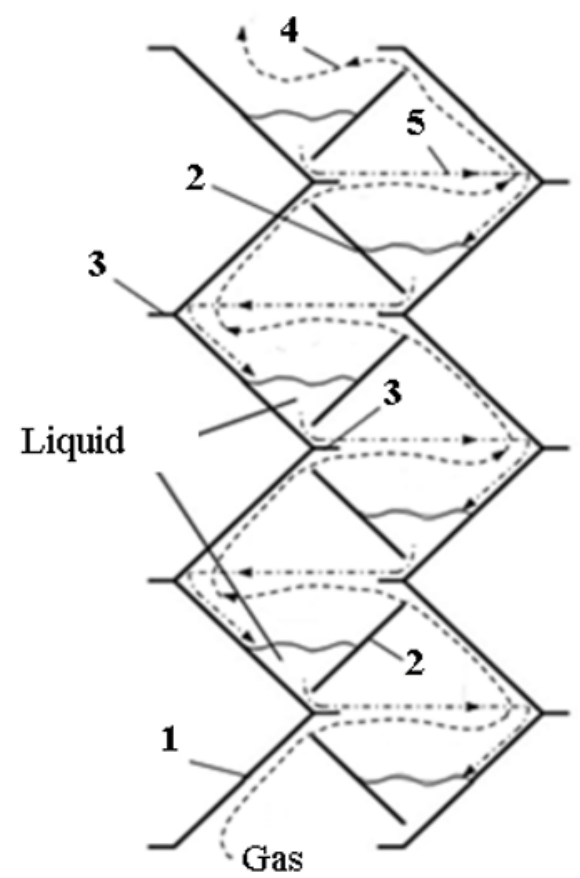

Fig. 1. Structural diagram of the regular packing: 1,2 - plates; 3 - horizontal pad; 4 - gas flow; 5 liquid flow

The complete factorial experiment has been conducted by the procedure described in $[5,6]$. The tests were aimed to determine the regression dependence of the sprayed packing bed's flow friction $\Delta p$ on the following factors: superficial gas velocity $w$ and liquid spray rate $U$.

Superficial gas velocity $(w, \mathrm{~m} / \mathrm{sec})$ is equal to the ratio between volume gas flow rate $\left(V, \mathrm{~m}^{3} / \mathrm{sec}\right)$ and full cross-section of a column $\left(S, \mathrm{~m}^{2}\right)[7]$ :

$$
w=\frac{V}{S} .
$$

Liquid spray rate $\left(U, \mathrm{~m}^{3} /\left(\mathrm{m}^{2} \cdot \mathrm{sec}\right)\right)$ is equal to the ratio between volume fluid flow rate $\left(V_{f}, \mathrm{~m}^{3} / \mathrm{sec}\right)$ and full cross-section of a column $\left(S, \mathrm{~m}^{2}\right)[8]$ :

$$
U=\frac{V_{f}}{S} \text {. }
$$

The flow friction of the sprayed packing bed is the optimization criterion in this case. 


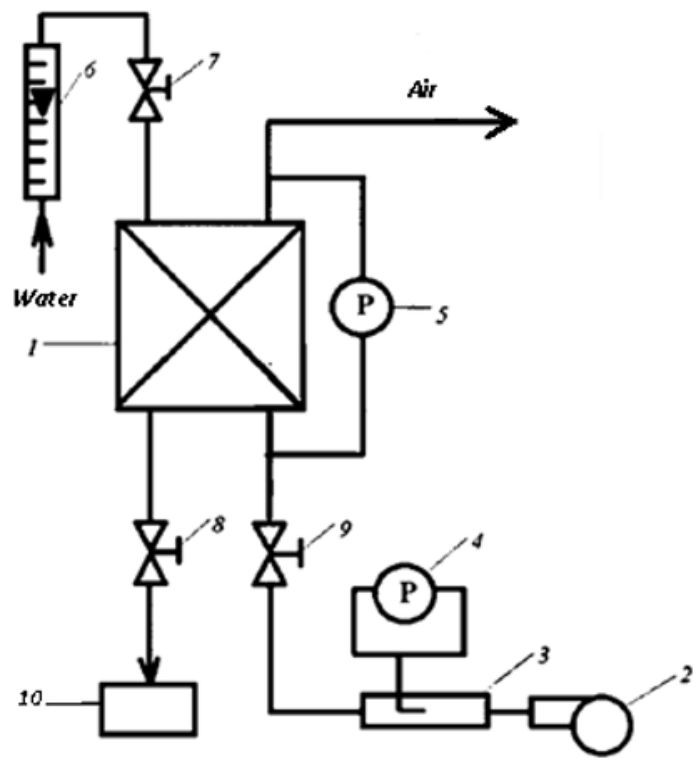

Fig. 2. Laboratory facility: 1 - regular packing; 2 - air blower; 3 - tube with Pitot-Prandtl tube; 4,5 micromanometer; 6 - variable-area flowmeter; 7-9 - valves; 10 - reservoir.

We shall find the response function in the form of [9]:

$$
\Delta p=b_{o}+b_{1} \cdot w+b_{2} \cdot U+b_{12} \cdot w \cdot U,
$$

where $\Delta p$ is the flow friction of the sprayed packing bed that is $1 \mathrm{~m}$ high, $\mathrm{Pa} / \mathrm{m}$. The term $b_{12} \cdot w \cdot U$ will be significant if conjunct influence of $w$ and $U$ on the optimization variable is not identical to their separate influence. The last term can be significant in our case since gas acts on the liquid distribution through the packing bed, and liquid acts on the gas redistribution in the packing bed section.

As a matter of priority, we should determine each factor's size of changing, hic est its lower and higher levels. For the "superficial gas velocity" factor, its lower level is 1.21 $\mathrm{m} / \mathrm{sec}$, and its higher level is $3.12 \mathrm{~m} / \mathrm{sec}$. For the "liquid spray rate" factor, its lower level will be $0.0080 \mathrm{~m}^{3} /\left(\mathrm{m}^{2} \cdot \mathrm{sec}\right)$, and its higher level will be $0.0304 \mathrm{~m}^{3} /\left(\mathrm{m}^{2} \cdot \mathrm{sec}\right)$. These factor scores are widely used during operation of commercial-scale packing-fitted equipment [10]. A complete factorial experiment is being conducted only for lower and higher factor levels [11].

Then we shall determine zero level (zero point) parameters (coordinates). Zero level parameters reside in the middle of factors' sizes of changing. Zero level parameters in this case are as follows: $w_{0}=2.165 \mathrm{~m} / \mathrm{sec}, U_{0}=0.0192 \mathrm{~m}^{3} /\left(\mathrm{m}^{2} \cdot \mathrm{sec}\right)$.

Next, the factors' variability interval is being determined: $\Delta w=0.955 \mathrm{~m} / \mathrm{sec} ; \Delta U=0.0112$ $\mathrm{m}^{3} /\left(\mathrm{m}^{2} \cdot \mathrm{sec}\right)$. Calculation data are tabulated in table 1 . 
Table 1. Layout of experiment, main parameters

\begin{tabular}{|l|c|c|}
\hline \multicolumn{1}{|c|}{ Parameter } & $\begin{array}{c}\text { Superficial gas velocity, } \\
\mathrm{m} / \mathrm{sec}\end{array}$ & $\begin{array}{c}\text { Liquid spray rate, } \\
\mathrm{m}^{3} /\left(\mathrm{m}^{2} \cdot \mathrm{sec}\right)\end{array}$ \\
\hline Zero level & 2.165 & 0.0192 \\
\hline Variability interval & 0.955 & 0.0112 \\
\hline Higher level level (encoded & 3.12 & 0.0304 \\
\hline $\begin{array}{l}\text { Higher } \\
\text { variables) }\end{array}$ & +1 & +1 \\
\hline Lower level level (encoded & 1.21 & 0.008 \\
\hline $\begin{array}{l}\text { Lower } \\
\text { variables) }\end{array}$ & -1 & -1 \\
\hline
\end{tabular}

Next, we embed intermediate (encoded) variables and tabulate their values in table 1:

$$
X_{1}=\frac{w-w_{0}}{\Delta w} \text { and } X_{2}=\frac{U-U_{0}}{\Delta U}
$$

In the process of a complete factorial experiment all parameters vary on two levels that conform with the encoded variables' values +1 and -1.In this case, the experiment is being conducted at gas velocity $1.21 \mathrm{~m} / \mathrm{sec}(-1)$ and $3.12 \mathrm{~m} / \mathrm{sec}(+1)$, liquid spray rate 0.0080 $\mathrm{m}^{3} /\left(\mathrm{m}^{2} \cdot \mathrm{sec}\right)(-1)$ and $0.0304 \mathrm{~m}^{3} /\left(\mathrm{m}^{2} \cdot \mathrm{sec}\right)(+1)$.

In view of encoded variables the sought for regression equation will be as follows:

$$
\Delta p=B_{o}+B_{1} \cdot X_{1}+B_{2} \cdot X_{2}+B_{12} \cdot X_{1} \cdot X_{2} .
$$

Table 2 shows experimental conditions of the complete two-factor experiment for the evaluation of the sprayed packing bed's flow friction. Columns 2 and 3 of table 2 are the experiment design matrix.

\begin{tabular}{|c|c|c|c|c|c|}
\hline \multirow[t]{2}{*}{ Test No, $i$} & \multicolumn{4}{|c|}{ Factors } & \multirow{2}{*}{$\begin{array}{c}\text { Optimization } \\
\text { criterion, } \Delta p_{i}, \mathrm{~Pa} / \mathrm{m}\end{array}$} \\
\hline & $\overline{X_{1}}$ & $X_{2}$ & $w, \mathrm{~m} / \mathrm{sec}$ & $U, \mathrm{~m}^{3} /\left(\mathrm{m}^{2} \cdot \mathrm{sec}\right)$ & \\
\hline 1 & 2 & 3 & 4 & 5 & 6 \\
\hline 1 & -1 & -1 & 1.21 & 0.008 & 182.2 \\
\hline 2 & +1 & -1 & 3.12 & 0.008 & 1285.3 \\
\hline 3 & -1 & +1 & 1.21 & 0.0304 & 213.0 \\
\hline 4 & +1 & +1 & 3.12 & 0.0304 & 1335.0 \\
\hline
\end{tabular}

Table 2. The complete two-factor experiment

The following principles were respected in the construction of complete factorial experiment matrix (columns 2 and 3 of table 2) [12]:

1. The variability levels of the first factor $X_{l}$ are being interchanged from test to test.

2. The interchange frequency of variability levels of each consecutive factor is half as much as the former's.

The total amount of tests in the design matrix:

$$
N=2^{n},
$$

where $n$ is the amount of factors. In the complete two-factor experiment the total amount of tests will be $N=4$.

The method of procedure has been as follows. The desired air flow rate has been adjusted with gas blower (2), valve (9) and differential pressure gage (4) (figure 2). The air flow rate $\left(\mathrm{m}^{3} / \mathrm{sec}\right)$ is estimated using readings of the micromanometer (4) fitted on the PitotPrandtl tube by the equation from publication [13]: 


$$
V_{A}=S \cdot \alpha \cdot\left(\frac{20 \cdot k_{\rho} \cdot \Delta p_{10} \cdot k_{T} \cdot k_{P}}{\rho_{A}}\right)^{0,5}
$$

where $\alpha$ is the field of velocities factor; $S$ is the sectional area, $\mathrm{m}^{2} ; \Delta p_{10}$ is the Pitot-Prandtl tube micromanometer gage readings; $k_{\rho}$ is the alcohol density ratio; $k_{T}$ is a correction factor; $\rho_{A}$ is an air density at operating conditions, $\mathrm{kg} / \mathrm{m}^{3} ; k_{P}$ is the slope ratio of the alcohol micromanometer tube.

Next, the packing bed (1) (figure 2) is being sprayed. Thereat, the packing bed (1) micromanometer gage (5) readings are being collected. Later, the liquid flow and spray rates are being changed with the valve (7), and the correspondent readings of pressure drop in the packing bed are being collected as well.

Column 6 of table 2 shows the results of experimental determination of the optimization criterion - the flow friction of the sprayed packing bed for every experimental condition.

Regression coefficients have been estimated using the following formulae from [14]:

$$
\begin{aligned}
& B_{0}=\frac{\sum_{i=1}^{N} \Delta p_{i}}{N}=\frac{1}{4} \cdot(182,2+1285,3+213,0+1335,0)=753,9 \\
& B_{1}=\frac{\sum_{i=1}^{N} X_{1} \cdot \Delta p_{i}}{N}=\frac{1}{4} \cdot(-182,2+1285,3-213,0+1335,0)=556,3 \\
& B_{2}=\frac{\sum_{i=1}^{N} X_{2 i} \cdot \Delta p_{i}}{N}=\frac{1}{4} \cdot(-182,2-1285,3+213,0+1335,0)=20,1 \\
& B_{12}=\frac{\sum_{i=1}^{N} X_{1 i} \cdot X_{2 i} \cdot \Delta p_{i}}{N}=\frac{1}{4} \cdot(182,2-1285,3-213,0+1335,0)=4,7
\end{aligned}
$$

Next, the coefficient significance is being determined, as some of coefficients could appear small to negligible. If the error of estimation of the regression coefficient is large while the coefficient itself is small, then such coefficient could probably be ignored [1517].

To determine the coefficient significance, it is essential to estimate the deviation (an error) of its determination:

$$
s_{b}^{2}=\frac{\bar{s}_{y}^{2}}{N}
$$

where $\bar{s}_{y}^{2}$ is the average deviation of optimization criterion. The results of the flow friction of the sprayed packing bed deviation estimation are shown in table 3 . The deviation has

\begin{tabular}{|c|c|c|c|c|}
\hline \multirow[t]{2}{*}{ Test No, $i$} & \multicolumn{2}{|c|}{$\begin{array}{c}\text { Parallel measurements results } \Delta p \text {, } \\
\qquad a / m\end{array}$} & \multirow{2}{*}{$\begin{array}{l}\text { Arithmetic mean } \Delta \bar{p} \text {, } \\
\qquad a / m\end{array}$} & \multirow[t]{2}{*}{ Deviation, $s_{y i}$} \\
\hline & I & II & & \\
\hline 1 & 175.0 & 189.4 & 182.2 & 103.68 \\
\hline 2 & 1276.6 & 1294.0 & 1285.3 & 151.38 \\
\hline 3 & 205.0 & 221.0 & 213.0 & 128.00 \\
\hline 4 & 1326.0 & 1344.0 & 1335.0 & 162.00 \\
\hline
\end{tabular}
been estimated using the equation:

$$
s_{y i}^{2}=\frac{\sum_{i=1}^{n}\left(\Delta p_{j i}-\Delta \bar{p}_{i}\right)^{2}}{k-1} .
$$

Table 3. The results of the flow friction of the sprayed packing bed deviation estimation (test numbers are same as in table 2) 
The average deviation for table 3 data will be: ${\overline{s_{y}}}^{2}=136.27$.

The number of degrees of freedom is related to the average deviation ${\overline{s_{y}}}^{2}$ :

$$
f=N \cdot(k-1)=4 \cdot(2-1)=4,
$$

where $N$ is the number of tests in the complete factorial experiment; $k$ is the number of parallel tests.

The error of estimation of the regression coefficient is determined via:

$$
s_{b}=\sqrt{\frac{\bar{s}_{y}^{2}}{N}}=\sqrt{\frac{136,27}{4}}=5,84 .
$$

As found in [6], the Student's t-test value for the probability belief $P=0.95$ and 4 degrees of freedom is $t=2.78$.

To estimate the significance of the regression coefficients, it is essential to compare coefficients with the product of $s_{b} \cdot t$. It is customary to assume that the regression coefficient is significant if the requirement is fulfilled:

$$
|B| \geq s_{b} \cdot t .
$$

If not, the regression coefficient is negligible and the corresponding term of the regression equation can be ignored.

Let's compare:

$$
\begin{aligned}
& \left|B_{0}\right|=753,9>s_{b} \cdot t ; \\
& \left|B_{1}\right|=556,3>s_{b} \cdot t ; \\
& \left|B_{2}\right|=20,1>s_{b} \cdot t \\
& \left|B_{12}\right|=4,7<s_{b} \cdot t
\end{aligned}
$$

Hence, all the regression coefficients except $B_{12}$ are significant. Thus, the last term $B_{12} \cdot X_{1} \cdot X_{2}$ of the regression equation (5) can be ignored and the encoded variables regression equation will be as follows:

$$
\Delta p=753,9+556,3 \cdot X_{1}+20,1 \cdot X_{2} .
$$

Having deduced the regression equation, it should be checked for sufficiency, i.e. the ability to match well enough with the test results [18-20].

To check the regression equation (21) sufficiency, let's find estimated values of the response function:

$$
\begin{aligned}
& \Delta p_{1}^{p}=753,9+556,3 \cdot(-1)+20,1 \cdot(-1)=177,48 \mathrm{~Pa} \\
& \Delta p_{2}^{p}=753,9+556,3 \cdot(+1)+20,1 \cdot(-1)=1290,03 \mathrm{~Pa} \\
& \Delta p_{3}^{p}=753,9+556,3 \cdot(-1)+20,1 \cdot(+1)=217,73 \mathrm{~Pa} \\
& \Delta p_{4}^{p}=753,9+556,3 \cdot(+1)+20,1 \cdot(+1)=1330,28 \mathrm{~Pa}
\end{aligned}
$$

Next, we will estimate the sufficiency deviation via:

$$
\begin{gathered}
s_{s d}^{2}=\frac{1}{N-C} \sum_{i=1}^{N}\left(\Delta p_{i}^{e}-\Delta \mathrm{p}_{i}^{c}\right)^{2}= \\
{\left[\begin{array}{l}
(182,2-177,48)^{2}+(1285,3-1290,03)^{2}+ \\
+(213-217,73)^{2}+(1335-1330,28)^{2}
\end{array}\right]=89,3}
\end{gathered}
$$

where $C$ is the amount of regression coefficients of the sought equation including the intercept term as well; $N$ is number of tests of the complete factorial experiment; $\Delta p_{i}{ }^{e}$ and 
$\Delta p_{i}{ }^{\mathrm{c}}$ are respectfully the experimental and calculated values of the response function in the $i$-th test.

The number of degrees of freedom is related to the sufficiency deviation:

$$
f_{s d}=N-C=1 .
$$

The regression equation can be sufficient if the requirement is fulfilled:

$$
F_{e}<F \text {, }
$$

where tabular Fisher's criterion $F=230.16$ (from [6]), and $F_{e}$ is the estimated Fisher's criterion.

The estimated Fisher's criterion is the following ratio:

$$
F_{e}=\frac{\max \left(s_{s d}^{2} ; \bar{s}_{y}^{2}\right)}{\min \left(s_{s d}^{2} ; \bar{s}_{y}^{2}\right)}=\frac{136,27}{89,3}=1,53
$$

As is obvious, the requirement (28) is fulfilled. Ergo, the regression equation (21) sufficiently matches with the test results.

By substituting equations (4) in regression equation (21) we will turn encoded variables into natural variables. The regression equation with natural variables will be as follows:

$$
\Delta p=-541,7+582,5 \cdot w+1796,9 \cdot U,
$$

because of:

$$
\begin{gathered}
b_{0}=B_{0}-\frac{B_{1} \cdot w_{0}}{\Delta w}-\frac{B_{2} \cdot U_{0}}{\Delta U}=-541,7 ; \\
b_{1}=\frac{B_{1}}{\Delta w}=582,5 ; \\
b_{2}=\frac{B_{2}}{\Delta U}=1796,9 .
\end{gathered}
$$

As can be seen from the above, the experimentally deduced regression equation (30) can be used to estimate the flow friction of the sprayed packing bed in the range of superficial gas velocity $1.21-3.12 \mathrm{~m} / \mathrm{sec}$ and liquid spray rate $0.0080-0.0304 \mathrm{~m}^{3} /\left(\mathrm{m}^{2} \cdot \mathrm{sec}\right)$. Given equation is destined to be utilized in the design and engineering process of absorbers with the shockspray packing.

\section{References}

1. A.V. Balchugov, M.V. Andreenko, A.V. Badenikov, I.E. Kuzora. Regular Packing for Heat and Mass Exchange Processes. Patent for the invention RU2602118, Published 10.11.2016, Bull. No. 31 (2016).

2. K.F. Pavlov, P.G. Romankov, A.A. Noskov. Examples and Problems to the Course of Unit Operations of Chemical Engineering. L., Chemistry. 552 p. (1976).

3. I. Iliuta, M.C. Iliuta. Enzymatic CO2 Capture in Countercurrent Packed-bed Column Reactors with High Performance Random Packings // International Journal of Greenhouse Gas Control, Volume 63, p. $462-474$ (2017).

4. M.V. Andreenko, A.V. Balchugov, D.A. Dubrovsky, V.V. Korobochkin. Mass Transfer Efficiency of Shock-spray Packing // Bulletin of the Tomsk Polytechnic University.Geo Assets Engineering. Volume 327, No. 11, p. 37-44 (2016). 
5. Yu.P. Adler. An introduction to experiment planning. / Adler Yu.P. Vvedenie v planirovanie eksperimenta. / Adler Y.P. Introduction to Experiment Design (in Russian). Metallurgy / Metallurgiya / MetalIndustry. 155 p. (1969).

6. S.N. Sautin. Planning an experiment in chemistry and chemical technology. / Sautin S.N. Planirovanie eksperimenta v khimii I khimicheskoy tekhnologii / Sautin S.N. Experiment Designin Chemistry and Chemical Technology (in Russian). L., Chemistry / Khimiya / Chemistry. 48p. (1975).Z. Guo, Z. Sun, N. Zhang, M. Ding, J. Liu. Pressure Drop in Slender Packed Beds with Novel Packing Arrangement // Powder Technology. Volume 321, p. 286-292 (2017).

7. I.A. Semenov, B.A. Ulyanov, D.N. Sitnikov, M.Yu. Fereferov. Plate Efficiency in Rectification of Binary Mixtures in the Presence of an Inert Gas // Russian Journal of Applied Chemistry. Volume 84, No. 12, p. 2071-2075 (2011).

8. F.J. Rejl, L. Valenz, J. Haidl, M. Kordač, T. Moucha. Hydraulic and masstransfer characteristics of Raschig Super-Pak $250 Y$ // Chemical Engineering Research and Design. No. 99, p. 20-27 (2015).

9. I.A. Semenov, B.A. Ulyanov, N.N. Kulov. Effect of Ultrasound on the Dissolution of Carbon Dioxide in Water // Theoretical Foundations of Chemical Engineering, Volume 45, No. 1, p. 21-25 (2011).

10. I.A. Semenov, B.A. Ulyanov, D.A. Dubrovskii, N.N. Kulov. Simulation of a Distillation Column with Nonequimolar Mass Transfer in the Production of Methylamines // Theoretical Foundations of Chemical Engineering. Volume 48, No. 5, p. 644-649 (2014).

11. Cui Gaochen, Jia Qing-Shan, Guan Xiaohong, Liuc Qing. Data-driven Computation of Natural Gas Pipeline Network Hydraulics // Results in Control and Optimization. Volume 1, December, 100004. (2020).

12. A. Pushnov, M. Berengarten, A. Sevryukov. Hydrodynamics of Packing Beds Made of Differently Structured Material for Thermal Utilization and Mass-Exchanged Processes in Columns of Environment Protection. // The 9th International Conference «Environmental engineering». Vilnius, Lithuania, p. 1-6. (2014).

13. E. Streltsova, A. Borodin, I. Yakovenko, T. Sokira, K. Bizhanova. Information Management System of Industrial Enterprise in Conditions of Digitalization // International Journal of Civil Engineering and Technology (IJCIET). Volume 10, Issue 01, January, p. 559-575. (2019).

14. Eric Machorro, Jichun Li, Monika Neda, Pengtao Sun, HongtaoYang. Recent Advances in Computational Mathematics and Applications // Results in Applied Mathematics. Volume 8, November, 100112 (2020).

15. H.A. Jensen, D.J. Jerez. A Stochastic Framework for Hydraulic Performance Assessment of Complex Water Distribution Networks // Probabilistic Engineering Mechanics. Volume 60, April, 103029 (2020).

16. N.R. Yusupbekov, F.T. Adilov, A.I. Ivanyan. Application of Cloud Technologies for Optimization of Complex Processes of Industrial Enterprises // 13th International 
Conference on Theory and Application of Fuzzy Systems and Soft Computing. ICAFS-2018, p.852-858 (2018).

17. R. Arnaud, M. Bouaifi and L. Gamet Hydrodynamics of Gas-Liquid Flows in Bubble Columns of Different Scales. Abstract format, The 3rd OpenFOAM User Conference, Stuttgart - Germany, p. 15-16 (2015).

18. B.G. Barjaktarović, M.N. Sovilj, S.S. Popović. Hydrodynamics and Axial Mixing in a Packed Gas-liquid Column Journal // Acta Periodica Technologica. No. 34, p. 33-48 (2003).

19. S. Chartona, M. Thebaulta, S.Winna, H. Roussela, F. Lamadiea, M.W. Hlawitschkab, C. Korbb, H.-J. Bartb. Hydrodynamics of Pulsed Columns: The Effect of New Parameters Affecting the Pressure Drop // Chemical Engineering Research and Design. Volume 125, p. 483-493 (2017). 